\title{
Statistical Methods Applied in Evaluating the Reliability of Land Surveying Equipment
}

\section{Introduction}

In solving practical land surveying issues related to testing the reliability of surveying equipment a need arises to verify statistical hypotheses regarding both the parameters and the mathematical distribution of the probability of errors in geodetic observations.

Two separate examples should be mentioned:

1) a statistical hypothesis specifies both the type and the distribution of its parameters,

2) a hypothesis is applied only to the mathematical form of the distribution function while the parameters are estimated using one of the methods of estimation [5].

To solve the above questions, statistical tests of conformity and identity may be used. They consist in comparing the empirical distribution (land surveying) with an assumed theoretical distribution, usually - a normal distribution.

A null hypothesis $H_{0}$ is proposed, concerning the compliance of the compared distributions, against an alternative hypothesis $H_{1}$ stating non-compliance of the distributions [6].

The compared distributions - empirical and theoretical - will generally differ, but the differences, in case the hypothesis $H_{0}$ is correct, should not be too large.

For the purposes of research, a characteristic $U[4,5]$, is constructed, acting here as a measure of differences between the compared distributions. Then, the critical region $S_{c r}$ is established that meets the following condition:

$$
P\left(u \in S_{c r}\right)=P_{c r}
$$

where $P_{c r}$ is the probability of rejection of $H_{0}$ in case it is correct; usually $P_{c r}=0.05$ is assumed.

\footnotetext{
* Rzeszów School of Engineering and Economics, Rzeszów, Poland
} 
Also in the case when $u$ calculated for a specified random sample is found within the critical area, hypothesis $H_{0}$ on the conformity of the compared distributions must be rejected.

When $u \notin S_{c r}$ - there are no grounds to reject $H_{0}$.

Among different statistical tests, the most well-known are the following conformity tests: $\chi^{2}$ Pearson and $\lambda$ Kolmogorov.

To test the accuracy of the measurements we performed by means of different instruments, some less well-known tests were used, namely, tests of identity:

- the Smirnov-Kolmogorov test,

- the rank sum test,

- the confidence intervals test.

\section{The Smirnov-Kolmogorov Test}

The Smirnov-Kolmogorov identity test is a statistical test of error distributions of two populations, based on two random samples with numbers $n_{1}$ and $n_{2}$. With empirical distribution functions marked as $S_{n 1}(x)$ and $S_{n 2}(x)$, respectively for the first and second sample - the tests statistic is:

where:

$$
D_{n 1^{\prime} n 2}=\sup \left|S_{n 1}(x)-S_{n 2}(x)\right|
$$

$D_{n 1^{\prime} n 2}-$ calculated test statistic,

$n_{1}-$ number of the first sample,

$n_{2}$ - number of the second sample,

$x$ - observations.

The critical set is the interval:

$$
\left[\mathrm{d}\left(\alpha, n_{1}, n_{2}\right) ; 1\right] .
$$

Critical values $\mathrm{d}\left(\alpha, n_{1}, n_{2}\right)$ multiplied by $n_{1}$ and $n_{2}$ for the significance level $\alpha=0.05$ can be found in statistical tables.

If values $D_{n 1^{\prime} n 2}$ are not within critical set, there are no grounds for rejecting the hypothesis on the normality of error distribution at significance level $\alpha$.

\section{Example 1}

The test in this study will be used to verify the accuracy of angle measurements performed with the electronic total station Leica TS 02 . The use of tests of identity in land surveying involves comparing the results of the measurements obtained with the tested device with the results from a previously verified instrument which operates correctly. 
For this purpose, the test instrument, Leica TS 02, was used to measure horizontal angles (in two runs at different alignments of the telescope) 26 times in a triangle, thereby obtaining deviations of 26 "triangles" and comparing them with the deviations from measurements of these same angles prior tested by means of a total station Topcon GTS-220 [2]. Measurements by the total station Topcon GTS-220 were performed in three series at different alignments of the telescope, on the same triangle base, and the collected results did not establish the presence of systematic errors in these measurements.

The structured results obtained in both tests are presented in Table 1

Table 1. Structured results of both samples

\begin{tabular}{|c|c|c|c|c|c|c|c|}
\hline \multirow[b]{2}{*}{$\begin{array}{c}x \\
{\left[{ }^{8}\right]}\end{array}$} & \multicolumn{2}{|c|}{ Number } & \multicolumn{2}{|c|}{ Cumulative number } & \multirow[b]{2}{*}{$S_{n 1}(x)$} & \multirow[b]{2}{*}{$S_{n 2}(x)$} & \multirow[b]{2}{*}{$\left|S_{n 1}(x)-S_{n 2}(x)\right|$} \\
\hline & $\begin{array}{l}1 \text { sample } \\
\text { Topcon }\end{array}$ & $\begin{array}{l}2 \text { sample } \\
\text { Leica }\end{array}$ & $\begin{array}{l}1 \text { sample } \\
\text { Topcon }\end{array}$ & $\begin{array}{c}2 \text { sample } \\
\text { Leica }\end{array}$ & & & \\
\hline-0.00180 & 0 & 1 & 0 & 1 & 0.0000 & 0.0556 & 0.0556 \\
\hline-0.00175 & 0 & 1 & 0 & 2 & 0.0000 & 0.1111 & 0.1111 \\
\hline-0.00160 & 1 & 0 & 1 & 2 & 0.0556 & 0.1111 & 0.0556 \\
\hline-0.00145 & 1 & 0 & 2 & 2 & 0.1111 & 0.1111 & 0.0000 \\
\hline-0.00140 & 1 & 1 & 3 & 3 & 0.1667 & 0.1667 & 0.0000 \\
\hline-0.00125 & 1 & 0 & 4 & 3 & 0.2222 & 0.1667 & 0.0556 \\
\hline-0.00090 & 1 & 0 & 5 & 3 & 0.2778 & 0.1667 & 0.1111 \\
\hline-0.00075 & 0 & 1 & 5 & 4 & 0.2778 & 0.2222 & 0.0556 \\
\hline-0.00050 & 1 & 0 & 6 & 4 & 0.3333 & 0.2222 & 0.1111 \\
\hline-0.00035 & 1 & 1 & 7 & 5 & 0.3889 & 0.2778 & 0.1111 \\
\hline-0.00025 & 1 & 0 & 8 & 5 & 0.4444 & 0.2778 & 0.1667 \\
\hline 0.00015 & 2 & 0 & 10 & 5 & 0.5556 & 0.2778 & $0.2778^{*}$ \\
\hline 0.00030 & 0 & 2 & 10 & 7 & 0.5556 & 0.3889 & 0.1667 \\
\hline 0.00060 & 0 & 1 & 10 & 8 & 0.5556 & 0.4444 & 0.1111 \\
\hline 0.00075 & 1 & 1 & 11 & 9 & 0.6111 & 0.5000 & 0.1111 \\
\hline 0.00085 & 0 & 1 & 11 & 10 & 0.6111 & 0.5556 & 0.0556 \\
\hline 0.00100 & 2 & 3 & 13 & 13 & 0.7222 & 0.7222 & 0.0000 \\
\hline 0.00115 & 1 & 0 & 14 & 13 & 0.7778 & 0.7222 & 0.0556 \\
\hline 0.00120 & 1 & 0 & 15 & 13 & 0.8333 & 0.7222 & 0.1111 \\
\hline 0.00130 & 1 & 1 & 16 & 14 & 0.8889 & 0.7778 & 0.1111 \\
\hline 0.00145 & 0 & 1 & 16 & 15 & 0.8889 & 0.8333 & 0.0556 \\
\hline 0.00150 & 1 & 0 & 17 & 15 & 0.9444 & 0.8333 & 0.1111 \\
\hline 0.00175 & 0 & 1 & 17 & 16 & 0.9444 & 0.8889 & 0.0556 \\
\hline 0.00185 & 1 & 0 & 18 & 16 & 1.0000 & 0.8889 & 0.1111 \\
\hline 0.00195 & 0 & 1 & 18 & 17 & 1.0000 & 0.9444 & 0.0556 \\
\hline 0.00215 & 0 & 1 & 18 & 18 & 1.0000 & 1.0000 & 0.0000 \\
\hline total & 18 & 18 & & & & & \\
\hline
\end{tabular}

* maximum difference of distribution 
Theoretical distribution leaps: 1:18 $=0.0556$.

Smirnov-Kolmogorov critical value tables provide as follows:

$$
n_{1} \cdot n_{2} \cdot \mathrm{d}\left(\alpha, n_{1}, n_{2}\right)=18 \cdot 18 \cdot \mathrm{d}(0.05,18,18)=162,
$$

it results, therefore, that $\mathrm{d}(0.05,18,18)=0.5$.

Thus, the critical interval is $[0.5,1]$, and the maximum difference of distribution is 0.2778 , which is not within the critical interval, which means that there is no reason to reject the hypothesis of conformity of distributions at the significance level $\alpha=0.05$.

The final conclusion of the test is, therefore, the absence of significant measurement errors, i.e. the tested total station Leica TS 02 is suitable for measuring angles.

The correctness of angle measurements made by Leica TS 02 was also verified by the Shapiro-Wilk test. According to [1], Kolmogorov and Pearson test do not use all the information that can be obtained from the present sample. In both tests, information is lost due to grouping the observations into classes. Moreover, $\chi^{2}$ Pearson's test does not take into account the differences $\left(n_{i}-n p_{i}\right)$ which are included in the test statistics, $\chi^{2}$ while the Kolmogorov test is based on only one difference, namely, the maximum absolute value of the difference $D_{n}$ - the test statistics. In contrast, the conformity test of random variable distribution from the sample with a normal distribution using the full information from the sample is the Shapiro-Wilk test [1].

Considering the above, to control the distribution of angular measurement errors made by Leica Total Station TS 02 - an additional Shapiro-Wilk statistical test of conformity will be applied.

In this test, the Shapiro-Wilk test statistic $W_{d}$ shall be used for the verification of the hypothesis of normal distribution of measurement errors - a random variable defined by the following formula [6]:

$$
W_{d}=\frac{\left(\sum_{i} a_{i}(n) \cdot\left(X_{n-i+1}-X_{i}\right)\right)^{2}}{\sum_{i}\left(X_{j}-\bar{X}^{2}\right.} \quad i=1, \ldots, \frac{n}{2}
$$

where:

$\left.X_{j}\right)$ - sample element values,

$a_{i}(n)$ - constants dependent on sample size and the value $i$ (summarized in Shapiro-Wilk tables).

If the statistical value $W_{d} W$ is within a critical area in the Shapiro-Wilk test, the hypothesis of normality is rejected at the significance level $\alpha$.

Otherwise, there is no reason to reject the hypothesis $H_{0}$. Structured results for "triangles" and calculations (for Example 1) are shown in Table 2. 
Table 2. Structured results for "triangles" and calculations for Example 1

\begin{tabular}{|c|c|c|c|c|c|c||}
\hline No. & $\begin{array}{c}X \\
{\left[{ }^{c}\right]}\end{array}$ & $X_{n-i+1}-X_{i}$ & $a_{i}(n)$ & $a_{i}(n) \cdot\left(X_{n-i+1}-X_{i}\right)$ & $X_{j}-\bar{X}$ & $\left(X_{j}-\bar{X}\right)^{2}$ \\
\hline \hline 1 & -18.0 & 39.5 & 0.4407 & 17.40765 & -20.2885 & 411.6232 \\
\hline 2 & -17.5 & 37.0 & 0.3043 & 11.25910 & -19.7885 & 391.5847 \\
\hline 3 & -16.0 & 34.5 & 0.2533 & 8.73885 & -18.2885 & 334.4692 \\
\hline 4 & -14.5 & 32.0 & 0.2151 & 6.88320 & -16.7885 & 281.8537 \\
\hline 5 & -14.0 & 29.0 & 0.1836 & 5.32440 & -16.2885 & 265.3152 \\
\hline 6 & -12.5 & 27.0 & 0.1563 & 4.22010 & -14.7885 & 218.6997 \\
\hline 7 & -9.0 & 22.0 & 0.1316 & 2.89520 & -11.2885 & 127.4302 \\
\hline 8 & -7.5 & 19.5 & 0.1089 & 2.12355 & -9.7885 & 95.8147 \\
\hline 9 & -5.0 & 16.5 & 0.0876 & 1.44540 & -7.2885 & 53.1222 \\
\hline 10 & -3.5 & 13.5 & 0.0672 & 0.90720 & -5.7885 & 33.5067 \\
\hline 11 & -2.5 & 11.0 & 0.0476 & 0.52360 & -4.7885 & 22.9297 \\
\hline 12 & 1.5 & 6.0 & 0.0284 & 0.17040 & -0.7885 & 0.6217 \\
\hline 13 & 3.0 & 3.0 & 0.0094 & 0.02820 & 0.7115 & 0.5062 \\
\hline 14 & 6.0 & - & - & - & 3.7115 & 13.7752 \\
\hline 15 & 7.5 & - & - & - & 5.2115 & 27.1597 \\
\hline 16 & 8.5 & - & - & - & 6.2115 & 38.5827 \\
\hline 17 & 10.0 & - & - & - & 7.7115 & 59.4672 \\
\hline 18 & 11.5 & - & - & - & 9.2115 & 84.8517 \\
\hline 19 & 12.0 & - & - & - & 9.7115 & 94.3132 \\
\hline 20 & 13.0 & - & - & - & 10.7115 & 114.7362 \\
\hline 21 & 14.5 & - & - & - & 12.2115 & 149.1207 \\
\hline 22 & 15.0 & - & - & - & 15.2115 & 161.5822 \\
\hline 23 & 17.5 & - & - & - & 19.21515 & 262.8127 \\
\hline 24 & 18.5 & - & - & -2115 & 296.2357 \\
\hline 25 & 19.5 & - & - & - & 369.0817 \\
\hline 26 & 21.5 & - & - & - & - & \\
\hline
\end{tabular}

$\bar{X}=2.2885 \quad \sum_{i=1}^{13} 61.92685 \quad \sum\left(X_{j}-\bar{X}^{2}=4140.5857\right.$

$$
\begin{gathered}
{\left[\sum_{i} a_{i}(n) \cdot\left(X_{n-i+1}-X_{i}\right)\right]^{2}=3834.9348} \\
W_{d}=\frac{3834.9348}{4140.5857}=0.926 .
\end{gathered}
$$


The critical range in the Shapiro-Wilk test is the interval $\left[0 ; W_{\alpha, n}\right]$. In this case, $W_{\alpha, n}=W_{0.05 ; 26}=0.920$ which can be found in Shapiro-Wilk statistical tables.

Since the calculated statistical value $W_{d}=0.926$ is outside the interval [0;920], there is no reason for rejection $H_{0^{\prime}}$ with a normal distribution of measurement errors, i.e. the tested instrument is suitable for use in measurments.

This result confirms the conclusion from the Smirnov-Kolmogorov test.

\section{T-test Checksum}

In order to verify whether the two random samples of the following observation numbers: the first one $\mathrm{n}_{1^{\prime}}$ the second $\mathrm{n}_{2^{\prime}}$ are characterized by the same distribution, the following steps are performed:

1. All observations from the two samples are set in a range of non-decreasing values and numbered, thus giving them rank. One can, then, calculate the sum of ranks of the elements for each sample separately. So, the value $T_{m}$ is acquired as the sum of consecutive numbers for the sample with a smaller size.

2. The checked null hypothesis was the assumption that there is no difference between the distributions of both general populations from which the samples were taken, so that the sum of the ranks of the smaller sample $\left(T_{m}\right)$ is to the sum of the ranks with a larger sample size, as the number of observations from a smaller sample $\left(n_{1}\right)$ is to the number of observations in the greater sample $\left(n_{2}\right)[8]$.

3. To test this hypothesis, we compare the resulting sum of the ranks of the smaller sample $\left(T_{m}\right)$ to the value $T$ which is found in the tables of critical values for the T-test, at a significance level $\alpha=0.05$. The critical region is the test interval $T\left(0 ; T_{\alpha}\right)$ - in this case $\left(0 ; T_{0.05}\right)$.

\section{Example 2}

In order to verify whether the height measurements made by the tested level Topcon AT G7N are not subject to systematic errors, 12 leveling measurements were carried out "from the middle" at a closed string of the length of approximately $1 \mathrm{~km}$ [3].

Thus, $n_{1}=12$ mesh values were obtained.

If the value $T_{m}$ is larger than $T_{\alpha}$ there is no reason to rejetc $H_{0}$.

In order to verify $H_{0}$ with equal distributions of errors of both series, in like manner $n_{2}=15$ height measurements were carried out with an electronic level Leica Sprinter 150 prior tested to be operating correctly.

The results of observation (mesh) acquired are presented in Table 3. 
Table 3. The results of observation for Example 2

\begin{tabular}{||c|c|c||}
\hline No. & $X_{i}[\mathrm{~mm}]$ Topcon & $X_{i}[\mathrm{~mm}]$ Leica Sprinter \\
\hline \hline 1 & -4.0 & +3.0 \\
\hline 2 & +2.5 & -1.5 \\
\hline 3 & +2.0 & 0.0 \\
\hline 4 & -1.0 & +2.5 \\
\hline 5 & -3.0 & -2.0 \\
\hline 6 & +0.5 & -1.0 \\
\hline 7 & -3.5 & -0.5 \\
\hline 8 & +3.0 & +1.0 \\
\hline 9 & -1.0 & -1.5 \\
\hline 10 & 0.0 & +3.0 \\
\hline 11 & -3.5 & -3.0 \\
\hline 12 & +3.0 & 0.0 \\
\hline 13 & - & -2.5 \\
\hline 14 & - & -2.0 \\
\hline 15 & - & +1.5 \\
\hline
\end{tabular}

Ascending results of both tests are as follows (middle row contains the results of measurements, the top row - marking a random sample, the lower row - the rank given):

\begin{tabular}{|c|c|c|c|c|c|c|c|c|c|c|c|c|c|}
\hline I & I & I & I & II & II & II & II & II & II & I & I & II & II \\
\hline-4.0 & -3.5 & -3.5 & -3.0 & -3.0 & -2.5 & -2.0 & -2.0 & -1.5 & -1.5 & -1.0 & -1.0 & -1.0 & -0.5 \\
\hline 1 & 2 & 3 & 4.5 & 4.5 & 6 & 7 & 8 & 9 & 10 & 12 & 12 & 12 & 14 \\
\hline \hline I & II & II & I & II & II & I & I & II & I & I & II & II & \\
\hline 0.0 & 0.0 & 0.0 & 0.5 & 1.0 & 1.5 & 2.0 & 2.5 & 2.5 & 3.0 & 3.0 & 3.0 & 3.0 & \\
\hline 16 & 16 & 16 & 18 & 19 & 20 & 21 & 22.5 & 22.5 & 25.5 & 25.5 & 25.5 & 25.5 & \\
\end{tabular}

Deviation -3.5 occurs in two cases, but because both are from the same series of measurements - they are numbered sequentially (numbers 2 and 3). Deviation -1.0 occurs in three cases, but it occurs twice in series 1 and once with series 2 . These three results should be assigned numbers 11, 12 and 13. Since, however, it does not matter in what order we put the results of series 1 and 2 - we computed a "common" number for these three results:

$$
\frac{11+12+13}{3}=\frac{36}{3}=12
$$

Total rank for the first (smaller) sample is:

$$
T_{m}=1+2+3+4.5+12+12+16+18+21+22.5+25.5+25.5=163 .
$$


Total rank for the second sample is:

$T_{2}=4.5+6+7+8+9+10+12+14+16+16+19+20+22.5+25.5+25.5=215$.

The sum of the two total ranks is:

$$
163+215=378 .
$$

The sum of consecutive numbers from 1 to 27 is equal to:

$$
s=\frac{n(n+1)}{2}=\frac{27 \cdot 28}{2}=378 \text {. }
$$

The compatibility of these sums is a checksum of the calculations made.

Sum $T_{m}$ i.e. the sum of ranks for the smaller sample is 163 , and the value $T$ from the test tables for $n_{1}=12$ and $n_{2}=15$, at a significance level $\alpha=0.05$ is 127 .

Therefore:

$$
T_{0.05}=127<T_{m}=163 .
$$

Thus, here is no basis to reject the null hypothesis $H_{0^{\prime}}$ i.e. the distributions of populations represented by the two samples are identical. If $T_{m}$ was less than 127, the sum of ranks of the larger sample would be greater than 251 , as $378-127=251$.

The difference of these sums would be too large, because the sum of the ranks should be in the same ratio as the number of tests, namely:

$$
\frac{n_{1}}{n_{2}}=\frac{12}{15}=0.80 \quad \text { and } \quad \frac{T_{m}}{T_{2}}=\frac{163}{215} \cong 0.76 .
$$

which is to a very large extent fulfilled.

In the event that $T_{0.05}$ was higher than $T_{m}$, would be:

$$
\frac{T_{m}}{T_{2}}=\frac{127}{215} \cong 0.51,
$$

which is significantly different from 0.80 .

Thence the inequality:

$$
T_{0.05}=127<T_{m}=163
$$

indicates a lack of evidence to reject $H_{0}$, i.e. the measurements do not include systematic errors and the tested level Topcon AT G7N is suitable for measurements without special rectification actions.

\section{Detection of Systematic Errors Using Confidence Intervals}

In order to check whether the results of measurements made by the tested equipment are not subject to systematic errors, we compared the results of measurements 
taken with the instruments with the results of measurements made by previously proven, correctly operating instrument.

Analyzing the results of the two series of measurements one can determine whether the tested differences do not exceed levels that would indicate the presence of systematic errors in the test equipment [4].

To this end, we constructed confidence intervals for a selected confidence level for the average value. On the basis of the value $Q$ calculated from the two series of measurements, we created two confidence intervals separately for each series, as their boundaries would be different due to the different average values $x_{1}$ and $+x_{2}$ (the ranges would be the same if the average of both series is equal; $x_{1}=x_{2}$ ).

For the calculations, we assume the null hypothesis $H_{0}$ that the average values are homogeneous (derived from the general population).

If the intervals partially overlap, the hypothesis $H_{0}$ can be considered true. In the absence of common areas in the intervals, the alternative hypothesis $H_{1}$ should be deemed as true, consisting in that the averages are not homogeneous, and hence that there are systematic errors in measurements.

\section{Example 3}

In two series, the distance between two stabilized points was measured 30 times. The first series of results was obtained from a previously proved Topcon GTS-220 total station, the second series - from the testes Leica TS 02 level [2]. The results are presented in the Table 4.

Table 4. Results of measurements for both series

\begin{tabular}{|c|c|c|c|c|c|c||}
\hline \multirow{2}{*}{ No. } & \multicolumn{3}{|c|}{ Series I } & \multicolumn{3}{c||}{ Series II } \\
\cline { 2 - 7 } & \multicolumn{3}{|c|}{ distance; Topcon GTS-220 } & \multicolumn{3}{c||}{ distance; Leica TS 02 } \\
\cline { 2 - 7 } & {$[\mathrm{m}]$} & $x_{i}-\bar{x}[\mathrm{~mm}]$ & $\left(x_{i}-\bar{x}\right)^{2}\left[\mathrm{~mm}^{2}\right]$ & {$[\mathrm{m}]$} & $x_{i}-\bar{x}[\mathrm{~mm}]$ & $\left(x_{i}-\bar{x}\right)^{2}\left[\mathrm{~mm}^{2}\right]$ \\
\hline \hline 1 & 83.693 & -0.5 & 0.25 & 83.687 & 1.3 & 1.69 \\
\hline 2 & 83.694 & 0.5 & 0.25 & 83.685 & -0.7 & 0.49 \\
\hline 3 & 83.693 & -0.5 & 0.25 & 83.685 & -0.7 & 0.49 \\
\hline 4 & 83.693 & -0.5 & 0.25 & 83.686 & 0.3 & 0.09 \\
\hline 5 & 83.693 & -0.5 & 0.25 & 83.686 & 0.3 & 0.09 \\
\hline 6 & 83.693 & -0.5 & 0.25 & 83.686 & 0.3 & 0.09 \\
\hline 7 & 83.693 & -0.5 & 0.25 & 83.686 & 0.3 & 0.09 \\
\hline 8 & 83.694 & 0.5 & 0.25 & 83.685 & -0.7 & 0.49 \\
\hline 9 & 83.694 & 0.5 & 0.25 & 83.685 & -0.7 & 0.49 \\
\hline 10 & 83.694 & 0.5 & 0.25 & 83.687 & 1.3 & 1.69 \\
\hline 11 & 83.694 & 0.5 & 0.25 & 83.685 & -0.7 & 0.49 \\
\hline 12 & 83.694 & 0.5 & 0.25 & 83.685 & -0.7 & 0.49 \\
\hline 13 & 83.693 & -0.5 & 0.25 & 83.685 & -0.7 & 0.49 \\
\hline
\end{tabular}


Table 4. cont.

\begin{tabular}{||c|c|c|c|c|c|c||}
\hline \multirow{2}{*}{ No. } & \multicolumn{3}{|c|}{ Series I } & \multicolumn{3}{c|}{ Series II } \\
\cline { 2 - 7 } & \multicolumn{3}{|c|}{ distance; Topcon GTS-220 } & \multicolumn{3}{c||}{ distance; Leica TS 02 } \\
\cline { 2 - 7 } & {$[\mathrm{m}]$} & $x_{i}-\bar{x}[\mathrm{~mm}]$ & $\left(x_{i}-\bar{x}\right)^{2}\left[\mathrm{~mm}^{2}\right]$ & {$[\mathrm{m}]$} & $x_{i}-\bar{x}[\mathrm{~mm}]$ & $\left(x_{i}-\bar{x}\right)^{2}\left[\mathrm{~mm}^{2}\right]$ \\
\hline \hline 14 & 83.693 & -0.5 & 0.25 & 83.685 & -0.7 & 0.49 \\
\hline 15 & 83.694 & 0.5 & 0.25 & 83.686 & 0.3 & 0.09 \\
\hline 16 & 83.694 & 0.5 & 0.25 & 83.686 & 0.3 & 0.09 \\
\hline 17 & 83.694 & 0.5 & 0.25 & 83.686 & 0.3 & 0.09 \\
\hline 18 & 83.694 & 0.5 & 0.25 & 83.686 & 0.3 & 0.09 \\
\hline 19 & 83.694 & 0.5 & 0.25 & 83.686 & 0.3 & 0.09 \\
\hline 20 & 83.693 & -0.5 & 0.25 & 83.685 & -0.7 & 0.49 \\
\hline 21 & 83.693 & -0.5 & 0.25 & 83.685 & -0.7 & 0.49 \\
\hline 22 & 83.693 & -0.5 & 0.25 & 83.686 & 0.3 & 0.09 \\
\hline 23 & 83.693 & -0.5 & 0.25 & 83.685 & -0.7 & 0.49 \\
\hline 24 & 83.693 & -0.5 & 0.25 & 83.685 & -0.7 & 0.49 \\
\hline 25 & 83.693 & -0.5 & 0.25 & 83.685 & -0.7 & 0.49 \\
\hline 26 & 83.693 & -0.5 & 0.25 & 83.686 & 0.3 & 0.09 \\
\hline 27 & 83.693 & -0.5 & 0.25 & 83.686 & 0.3 & 0.09 \\
\hline 28 & 83.694 & 0.5 & 0.25 & 83.687 & 1.3 & 1.69 \\
\hline 29 & 83.694 & 0.5 & 0.25 & 83.687 & 1.3 & 1.69 \\
\hline 30 & 83.694 & 0.5 & 0.25 & 83.686 & 0.3 & 0.09 \\
\hline $\bar{x}$ & 83.6935 & -1.0 & 7.500 & 83.6857 & 0.0 & 14.300 \\
\hline
\end{tabular}

Mean error for individual observations is:

- for measurements by Topcon GTS-220 (series I): $\bar{m}_{I}=0.5085 \mathrm{~mm}$

- for measurements by Leica TS 02 (series II): $\bar{m}_{I I}=0.7022 \mathrm{~mm}$

$$
\begin{gathered}
\bar{x}_{I I}-\bar{x}_{I}=-0.0078 \mathrm{~m}, \\
\alpha=0.05 .
\end{gathered}
$$

For both series, we construct the confidence intervals for mean value:

$$
Q_{X_{I}}=\frac{\bar{m}_{I}}{\sqrt{n_{I}}}=0.09 \mathrm{~mm} ; \quad Q_{X_{I I}}=\frac{\bar{m}_{I I}}{\sqrt{n_{I I}}}=0.13 \mathrm{~mm} .
$$

Student's distribution tables provide the value $t_{0.05 / 29}=2.045$.

The confidence interval of the mean for series 1 shall be:

$P\left(\bar{x}_{I}-t_{\alpha_{I} / n-1} \cdot Q_{X_{I}} \leq \alpha \leq \bar{x}_{I}+t_{\alpha_{I} / n-1} \cdot Q_{X_{I}}\right)=1-\alpha$

$P(83.6935-2.045 \cdot 0.00009 \leq \alpha \leq 83.6935+2.045 \cdot 0.00009)=0.95$,

$P(83.6933 \leq \alpha \leq 83.6937)=0.95$. 
The confidence interval of the mean for series 2 shall be:

$$
\begin{aligned}
& P\left(\bar{x}_{I I}-t_{\alpha_{I I} / n-1} \cdot Q_{X_{I I}} \leq \alpha \leq \bar{x}_{I I}+t_{\alpha_{I I} / n-1} \cdot Q_{X_{I I}}\right)=1-\alpha \\
& P(83.6857-2.045 \cdot 0.00013 \leq \alpha \leq 83.6857+2.045 \cdot 0.00013)=0.95, \\
& P(83.6854 \leq \alpha \leq 83.6860)=0.95 .
\end{aligned}
$$

These intervals do not overlap, which implied the need to reject $H_{0}$ at level $\alpha=0.05$, i.e. that distance measurements made by the test instrument involve systematic errors.

\section{Conclusions}

1. The study of angle measurements made by the electronic total station Leica TS 02 showed, using the Kolmogorov-Smirnov test of identity, an absence of systematic errors.

2. The conducted additional test results from the same measurements using the Shapiro-Wilk test of conformity confirmed the conclusion from the SmirnovKolmogorov test about the absence of systematic errors.

3. Used to test the accuracy of the leveling measurements, the checksum T-rank identity test lead to the conclusion of the absence of systematic errors, and thus on the correctness of operation of the tested Leica Sprinter $150 \mathrm{M}$.

4. Accuracy studies of distance measurements made by Leica Total Station TS 02, carried out a according to a statistical test of confidence intervals, showed that the tested instrument should be rectified before performing measurements of distance.

5. Due to the fact that the Shapiro-Wilk test statistics $W_{d}$ adopted a value very close to the critical area of the test $W_{d}=0.926$ and the critical area is the interval $[0,920])$, we can conclude that the Shapiro-Wilk test is "stronger" than the Smirnov-Kolmogorov test, which in turn leads to the conclusion that it is important to properly select statistical tests to research.

6. The research has led to the general conclusion that in addition to conformity testing of land surveying equipment one can also apply statistical tests of identity.

\section{References}

[1] Banasik P., Cichociński P., Czaja J., Góral W., Kozioł K., Krzyżek R., Kudrys J., Ligas M., Skorupa B.: Podstawy geomatyki. Wydawnictwa AGH, Kraków 2011.

[2] Ćwikła T.: Badanie poprawności pomiarów kątowych wykonywanych tachimetrem Leica TS 02, z pomoca testów statystycznych [unpublished engineering work prepared under the supervision of W. Krupiński]. UR, Kraków 2012. 
[3] Gawlik J., Stachnik K.: Statystyczne sposoby kontroli poprawności działania instrumentów i metod pomiarów geodezyjnych [unpublished engineering work prepared under the supervision of W. Krupiński]. WSIE, Rzeszów 2009.

[4] Greń J.: Modele i zadania statystyki matematycznej. PWN, Warszawa 1970.

[5] Kaczmarek Z.: Metody statystyczne hydrologii i meteorologii. WKiŁ, Warszawa 1970.

[6] Ney B.: Kryteria zgodności rozkładów empirycznych z modelami. ZN PAN, Geodezja 7, Kraków 1970.

[7] Piasek Z.: Geodezja budowlana dla inżynierii środowiska. ZN PK, Kraków 2000.

[8] Puchalski T.: Statystyka. PWN, Warszawa 1969. 